\title{
Etiology of Apple Sooty Blotch Disease in North Carolina
}

\author{
E. M. Johnson, T. B. Sutton, and C. S. Hodges
}

Department of Plant Pathology, North Carolina State University, Raleigh 27695-7616.

Current address of E. M. Johnson: Monsanto Agricultural Company, 800 North Lindbergh Blvd., St. Louis, MO 63167.

Accepted for publication 10 October 1996.

\begin{abstract}
Johnson, E. M., Sutton, T. B., and Hodges, C. S. 1997. Etiology of apple sooty blotch disease in North Carolina. Phytopathology 87:88-95.

Sooty blotch disease of apples (Malus $\times$ domestica), previously attributed to the fungus Gloeodes pomigena, was shown to be a disease complex caused by fungi previously considered mycelial types of G. pomigena. Peltaster fructicola and Geastrumia polystigmatis were associated with the ramose mycelial type. A fungus similar to $P$. fructicola, but with smaller pycnothyria and conidia, was associated with the punctate myce-

lial type. The diffuse fuliginous mycelial type was caused by Leptodontium elatius. Fungi that fit the classical morphological description of $G$. pomigena were not observed. Pycnothyria of $P$. fructicola developed on overwintered colonies on blackberries, and conidia were a source for primary infection during the entire growing season. Secondary spread was through conidia produced in colonies on fruit. L. elatius was observed infrequently producing conidia on fruit during periods of extended high moisture. Histological examination did not reveal penetration of the cuticle of apple fruit for any of the fungi of the apple sooty blotch complex.
\end{abstract}

Sooty blotch of apple (Malus $\times$ domestica Borkh.), attributed to the fungus Gloeodes pomigena (Schwein.) Colby, is a superficial blemish on fruit that is found throughout the world (18). It has been studied by many researchers since it was first described as being caused by Dothidea pomigena Schwein. on cv. Newtown Pippin apples in Connecticut by Schweinitz in 1832 (10). Most investigations have focused on control strategies, because sooty blotch annually causes significant quality loss in fruit where the disease is not managed. Few investigations have been conducted, however, that focus on the biology of the fungus. In 1920, Colby (3) working in Illinois conducted a series of investigations to better understand the nature of sooty blotch. At that time, sooty blotch and flyspeck, caused by Schizothyrium pomi (anamorph Zygophiala jamaicensis), were believed to be caused by the same fungus. Characterization of reproductive morphology led Colby (3) to conclude that sooty blotch and flyspeck were the result of infections by different fungi. A new genus, Gloeodes, based on D. pomigena, was created to accommodate the sooty blotch pathogen. In his detailed report, Colby (3) also noted a diverse range in the gross morphology of sooty blotch colonies on fruit.

To our knowledge, no studies have been conducted subsequently to confirm Colby's (3) observations, and no other species within this genus has been described. Subsequent researchers $(1,7,9,12$, 19) have examined the disease in the context of Colby's conclusions. Each reported on the variability of symptoms associated with the disease. Shortly after Colby's (3) work, Zaring (19), Baines (1), and Baines and Gardner (2) working in Indiana reported the isolation and culture of $G$. pomigena. They encountered extreme difficulty in isolating the fungus, and each went to great lengths to develop techniques that were satisfactory in reducing the number of contaminants that reduced their recovery rate. Both researchers reported collecting the fungus from numerous reservoir hosts, including blackberries (Rubus spp.).

Groves (7) observed variation in mycelial morphology on both the surface of fruit and in culture. He provided detailed descriptions of mycelial growth patterns on fruit and categorized the pat-

Corresponding author: T. B. Sutton; E-mail address: tsutton@wolf.ces.ncsu.edu

Publication no. P-1996-1202-01R

(C) 1997 The American Phytopathological Society terns into four mycelial types-punctate, ramose, fuliginous, and rimate - based on the mycelial morphology of the fungus. Designation of these mycelial types has been adopted by subsequent researchers $(9,16,17)$. Groves (7), and later Hickey (9), conducted extensive research with cultures of $G$. pomigena, investigating their diversity with respect to physiological characters.

Paramount to plant pathology investigations is the need to accurately determine the etiology of a disease. For this reason, Koch's postulates are usually used to demonstrate that the organism isolated causes the observed symptoms. In most cases, sooty blotch has been reported to be the result of an epiphytic association of $G$. pomigena with the host. Consequently, symptoms of sooty blotch are actually composed entirely of fungal signs $(2,3,18)$. This makes it difficult to fulfill Koch's postulates, because any changes in the environment may alter fungal growth and the appearance of symptoms. Thus, laboratory investigations do not duplicate the natural environment, and field studies may not duplicate the environment in which the original colony developed. Both Baines (1), Baines and Gardner (2), and Hickey (9) were successful in completing Koch's postulates with isolates they collected, and each noted that the reproduced symptoms were similar to the original ones. However, neither gave a clear description of the morphological characteristics of their isolates in culture nor did they adequately describe the reproductive morphology of the fungus on apple fruit. In this paper, we use the clinical term "symptoms" in describing disease development.

Variability in colony morphology of sooty blotch has been noted in North Carolina for many years. Sutton (16) observed in routine fungicide screening trials that some mycelial types were less susceptible to some fungicides than others. Sutton (16) also observed that the relative distribution of mycelial types varied among orchards and geographic regions. In a study involving eight orchards, the incidence and severity of the various mycelial types correlated differently with measures of temperature and moisture (17). This result led the authors to hypothesize that the mycelial types may be associated with different fungi.

The etiology of sooty blotch in North Carolina has not been examined critically. A review of the literature revealed few detailed descriptions of the reproductive structures associated with various colony types of the sooty blotch fungi. The objective of this study was to examine the variation observed in sooty blotch 
on apples in North Carolina with emphasis on describing reproductive morphology of the causal agents to provide a better understanding of symptom variability.

\section{MATERIALS AND METHODS}

Characterization of symptom diversity. Apple fruit and blackberry (Rubus argutus Link) stems were collected at various times during the growing seasons from 1990 to 1993 at multiple locations in the Mountain, Piedmont, and Coastal Plain regions of North Carolina. Individual sooty blotch colonies were examined for vegetative characteristics, including mycelial arrangement; number, size, and arrangement of pycnothyria (apparently immature pycnothyria were termed plectenchymal bodies by Groves [7]); presence of conidia or conidiophores; and overall colony association with the fruit. Colonies were classified as fuliginous, ramose, punctate, or rimate with the aid of a dissecting microscope according to the system developed by Groves (7).

Symptom development over time. Fruit expressing sooty blotch symptoms were collected from the Central Crops Research Station located in Johnston County, NC, on 10 August 1992. Distinct immature and mature colonies, 10 and 25, respectively, representing ramose and punctate mycelial types were marked. Maturity was a qualitative assessment of development. Typically, immature colonies were not visible without the aid of a $\times 10$ hand lens, and mature colonies were visible without magnification. Using a dissecting microscope, data were taken on colony diameter at the widest point, percentage of total surface area within the perimeter of the colony covered with mycelium as a measure of subiculum density, and number of immature and mature pycnothyria. Pycnothyria were considered mature when they displayed a distinct rupture in the cellular plate or projected above the fruit surface. All colonies were photographed and classified according to the Groves' system (7). Fruit was placed in a dew chamber set to cycle $18 \mathrm{~h}$ wet $/ 6 \mathrm{~h}$ dry periods. Air temperature was 28 and $23^{\circ} \mathrm{C}$ during the dry and wet periods, respectively. Incandescent lights $\left(387 \mu \mathrm{E} \mathrm{m}^{-2}\right.$ $\mathrm{s}^{-1}$ ) were on during the dry period. After 14 days, colonies were measured and photographed.

Fungal colony morphology. Representative colonies of punctate, ramose, fuliginous, and rimate types were selected for morphological description of fungal structures. Pycnothyria were excised from the thallus with a fine dissecting needle. Squash preparations were made in lactophenol with cotton blue and were examined with bright-field and differential interference microscopy for details of asexual and sexual reproductive features. Conidial shape, size, and origin were recorded for anamorphic states.

Whole mounts of colonies were made by carefully excising the epidermis of apple fruit or blackberry stems and mounting in lactophenol under a glass coverslip. Detailed descriptions of mycelial arrangement of the subiculum and pycnothyria were recorded. The diameters of 5 pycnothyria in the centers of 15 colonies were measured with an ocular micrometer.

Cross-sections of specimens representing all observed types of colony morphologies were prepared. Sections ( 7 to $10 \times 7$ to 10 $\mathrm{mm}$ ) of fruit surfaces or blackberry stems containing the colonies were excised and fixed in a mixture of 2-propanol, water, propionic acid, and formaldehyde (45:45:5:5, vol/vol), dehydrated in a standard propanol schedule, and embedded in Paraplast-Plus (Curtin Matheson Scientific, Cleveland). Sections were cut at 12 $\mu \mathrm{m}$ on a rotary microtome, mounted on glass slides with Haupt's adhesive, and cleared with xylene. Sections were examined with bright-field and differential interference microscopy to determine the relationship of the fungus with the host tissue and the internal structure and development of the pycnothyria.

Species determination. Some of the fungi associated with sooty blotch were identified on apple peel and Rubus stems by B. Sutton and A. Sivanesan at the International Mycological Institute (IMI) (Bakeham Lane, Egham, Surrey, England) and when possible com- pared with herbarium specimens, borrowed from the National Fungus Collection (BPI) (Systematic Botany and Mycology Laboratory, Beltsville, MD), and the Farlow Cryptogamic Herbarium (Harvard University, Cambridge, MA) for confirmation of identity.

Overwintering on apple fruit and blackberry stems. Fruit were collected from the Central Crops Research Station, Johnston County, NC, and Mountain Horticultural Crops Research Station, Henderson County, NC, during the fall of 1991 and 1992. Distinct ramose and punctate colonies of sooty blotch were located under a dissecting microscope in the laboratory, circled with a permanent marking pen, and labeled. Fruit were placed in cold storage at $4^{\circ} \mathrm{C}$ until the average daytime temperature outside fell below $15^{\circ} \mathrm{C}$. Fruit then were transferred to wire cages under the canopy of apple trees at the Mountain Horticultural Crops Research Station in 1991 and outside the greenhouse complex on the North Carolina State University campus in 1992. Fruit were retrieved from the cages once a month during January, February, March, and every other week in April and May to examine the sooty blotch colonies for development of reproductive structures. Similarly, blackberry stems on a ditch bank in eastern Wake County, NC, heavily covered with sooty blotch were sampled over the winter during 1992 and 1993 and examined for development of reproductive structures.

On 4 and 18 March and 2 April 1993, fruit and common blackberry stems were placed on a coarse sand bed in clay pots in a glasshouse mist bed. Specimens were kept constantly moist with intermittent misting at a temperature of 24 to $28^{\circ} \mathrm{C}$. After 10 days, fruit were examined for reproductive structures as above.

Isolates and isolation techniques. Isolates (215) collected in a previous study (16) were augmented with additional specimens collected during 1991 to 1993 from colonies documented with thorough morphological descriptions and photographs. Each isolate was placed into one of three distinct categories based on differences in position of mycelial growth relative to the medium (potato dextrose agar [PDA]) and conidial production: immersed with conidia, immersed without conidia, and superficial with conidia.

Two isolation methods were employed that took into consideration the slow growth of the sooty blotch fungi and their sensitivity to all surface disinfestants $(1,7,9,16)$. Method 1 utilized $2.0 \%$ water agar (AWA) acidified with 50\% lactic acid ( 4 drops/100 ml of water agar), which retarded growth of contaminants such as Alternaria and Penicillium spp. and bacteria. Pycnothyria and small hyphal segments were excised with a sterile needle from each colony and transferred directly to AWA. After 2 days of incubation at $24^{\circ} \mathrm{C}$ in the dark, each colony was examined at $\times 100$ under a compound microscope, and selections were made based on hyphal similarity to other colonies in the culture dish and direct association of new hyphal growth with the original fungal tissue. These colonies were transferred to a second AWA dish and grown in the dark at $24^{\circ} \mathrm{C}$ for 14 days prior to final transfer to PDA dishes and storage on PDA slants at 22 to $27^{\circ} \mathrm{C}$.

Method 2 was used in 1993 to make isolations from sooty blotch colonies on blackberry canes and apple fruit. A 5- $\mu$ drop of sterile water was applied with a micropipette to the surface of a colony with mature pycnothyria. After $20 \mathrm{~s}$, pycnothyria opened naturally to expose conidia. Using a dissecting microscope, a fine dissecting needle was used to dislodge conidia from the pycnothyria into the water droplet. The droplet was carefully removed with the micropipette and applied to the surface of AWA in a petri dish. A sterile, bent glass rod was used to spread the droplet across the surface of the dish. Final isolation was made by transferring colonies to AWA and PDA as described above.

Pathogenicity of isolates on apple fruit. Fifty isolates from our culture collection, representing the variation observed in culture, were used to test for pathogenicity on detached apple fruit. Of the isolates, 18 were characterized as immersed with conidia, 24 as superficial with conidia, and 8 as immersed without conidia. An inoculum suspension for each isolate was prepared from 14-day-old colonies grown on PDA by grinding the cultures in sterile deion- 
ized water with short bursts from a high speed blender and filtering the resultant suspension through six layers of cheesecloth. Inoculum suspensions were standardized to $5 \times 10^{5}$ propagative units per $\mathrm{ml}$ of sterile deionized water containing $0.5 \%$ apple juice and $0.1 \%$ Tween 20. Propagative units consisted of conidia and mycelial fragments.

Cv. Golden Delicious apples collected 2 weeks prior to harvest were utilized as the host in this study. To minimize potential interference from chemical residues and natural sooty blotch infection, fruit, which had received only early season sprays of myclobutanil (Nova 40W, $7.5 \mu \mathrm{g}$ a.i./ml), were obtained from Michigan, where sooty blotch is not as severe as in North Carolina. The surface of each fruit was disinfested by dipping the entire fruit in $70 \%$ ethanol, followed by rinsing in deionized water. Each fruit was marked with five 25 -mm-diameter circles that served as inoculation zones. Each inoculation zone was examined with a dissecting microscope for signs of natural infection by sooty blotch. An inoculum suspension was applied to each inoculation zone with a cotton swab and allowed to air-dry. Four zones were inoculated on each fruit; the fifth zone on each fruit, swabbed with sterile deionized water, served as a control.

Four fruit were inoculated with each isolate. Apples were atomized lightly with sterile deionized water and placed in a dew chamber. The chamber was set to cycle $18 \mathrm{~h}$ wet/ $6 \mathrm{~h}$ dry periods. Air temperature was 28 and $23^{\circ} \mathrm{C}$ during the dry and wet periods, respectively. Incandescent lights $\left(387 \mu \mathrm{E} \mathrm{m}^{-2} \mathrm{~s}^{-1}\right)$ were on during the dry period. Fruit were examined at 7 and 14 days after inoculation and scored for sooty blotch symptoms and type of sooty blotch colonies found within the inoculation zone. Isolations were made for those zones expressing sooty blotch symptoms, and resultant cultures were compared with the cultures originally used for inoculum production.

Field inoculations were conducted at the Central Crops and Mountain Horticultural Crops Research stations during 1992. Three isolates from each of the three isolate categories (immersed with conidia, immersed without conidia, and superficial with conidia) were selected for these studies. Inoculum suspensions were prepared as in detached fruit studies. Clusters of three fruit on each of four separate

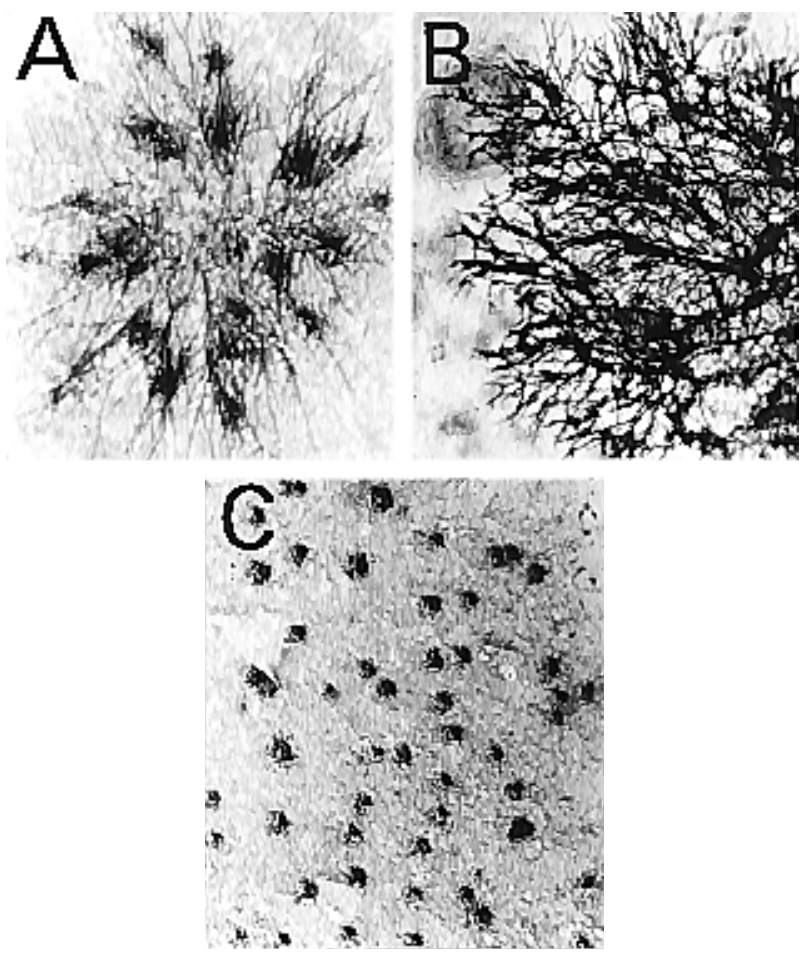

Fig. 1. Thallus morphology of ramose colonies. A, Ramose colony exhibiting typical radial growth pattern, distinct margins, and pycnothyria $(\times 39)$; $\mathbf{B}$, arborescent branching of ramose colonies, which is characteristic of the margin of the colony $(\times 50)$; and $\mathbf{C}$, immature pycnothyria in a ramose colony $(\times 39)$. trees were inoculated with each isolate by a compressed-air atomizer. Sterile deionized water with $0.5 \%$ apple juice was used as the control. Inoculations were made on 8 and 22 May, 8 and 19 June, and 6 July at Central Crops Research Station and on 12 and 26 May and 9 and 23 June at the Mountain Horticultural Crops Research Station. Only maintenance insecticide applications were made during the growing season on the trees used for inoculation. Fruit were harvested in mid-September and scored for percentage of total surface area covered with sooty blotch and proportion of total sooty blotch composed of fuliginous, punctate, ramose, and rimate colonies.

Characterization of sooty blotch on fruit from areas outside North Carolina. Fruit (10 to 15) exhibiting symptoms of sooty blotch were obtained from each of 10 states (Massachusetts, New York, Michigan, Missouri, Illinois, Indiana, Ohio, West Virginia, Pennsylvania, and Virginia) during the fall of 1992 and from each of nine states (New York, Virginia, Michigan, Ohio, Illinois, Kentucky, Massachusetts, Missouri, and Alabama) during the fall of 1993. Disease severity, overall and by mycelial type, was evaluated on each fruit by estimating the percent surface area affected. Mycelia and pycnothyria were examined, and fungi were identified as described above with whole colony and squash mounts for morphological comparison with similar colonies from North Carolina. Isolations were made from samples examined in 1992 for comparison of cultural characteristics with those of isolates from North Carolina.

\section{RESULTS}

Characterization of symptoms. Colony morphology on apple fruit and blackberry stems varied within and among collection locations. Ramose, punctate, and fuliginous colonies (Groves' system

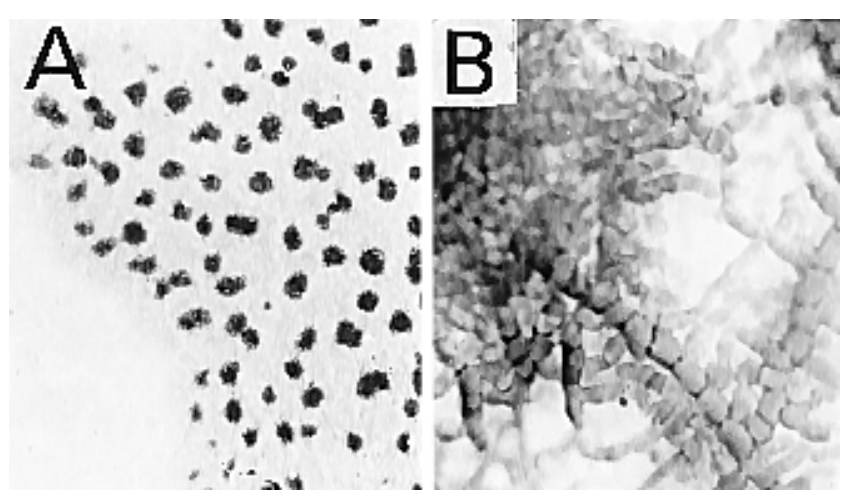

Fig. 2. Thallus morphology of punctate colonies. A, Punctate colony exhibiting numerous immature pycnothyria and a reticulate thallus $(\times 23)$; and $\mathbf{B}$, irregular shaped cells anastomosed to form a cell plate between the reticulate hyphal network in punctate colonies $(\times 285)$.

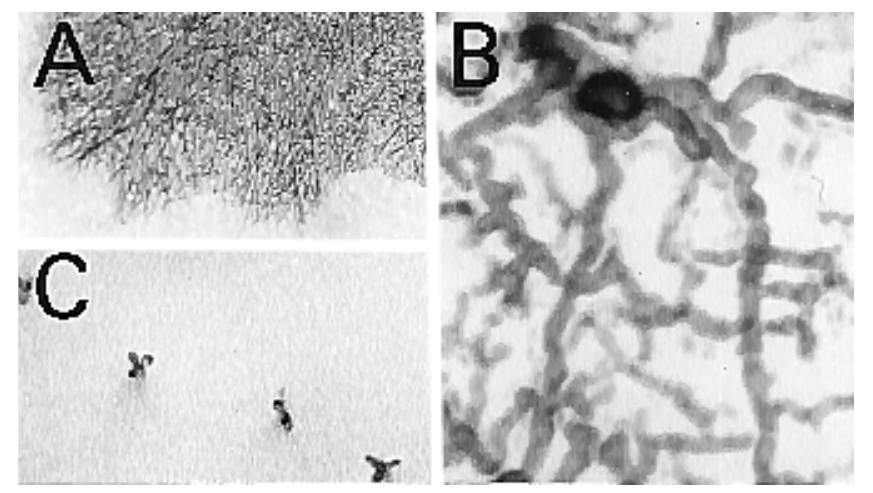

Fig. 3. Thallus morphology of fuliginous colonies. A, A moderately dense fuliginous colony appears smoky, with a characteristic lack of pycnothyria $(\times 21)$; B, typical reticulate hyphal network of a fuliginous colony $(\times 462)$; and $\mathbf{C}$, Three to five conidia are produced sympodially on the terminus of the conidiophore $(\times 320)$. 
[7]) were observed on the surface of apple fruit. Rimate colonies that penetrated the cuticle were not observed. Colonies with a network of dark mycelial ridges that superficially resembled the rimate type were observed, but histological examination did not reveal disruption of the cuticle. Sooty blotch colonies on blackberries and red apples were not as distinct as those observed on apples with green or yellow skins and were less amenable to visual classification of mycelial types.

The thallus of ramose colonies exhibited a strong radial growth pattern. Hyphae were branched repeatedly in an arborescent pattern (Fig. 1A). Primary branches usually were composed of multiple, parallel hyphal strands that often fused. The arborescent growth pattern became obscured as colonies matured but was present consistently at the margins of distinct colonies (Fig. 1B). The arborescent and radial nature of the colonies was more difficult to discern on blackberry stems than on apple fruit. Colonies often coalesced with other sooty blotch colonies of the same or different types by the end of the season, giving the overall appearance of large blotched regions on apple surfaces and blackberry stems. Ramose colonies always contained pycnothyria (Fig. 1C).

Thalli of punctate colonies were always conspicuously covered with pycnothyria that were generally smaller than those observed in ramose colonies (Fig. 2A). The thallus consisted of a reticulate network of mycelium in which the interstitial areas were sometimes filled with dense, irregular shaped cells (Fig. 2B). Margins of punctate colonies were distinct with little or no arborescent character. Colonies appeared to increase in size secondarily through conidial infections.
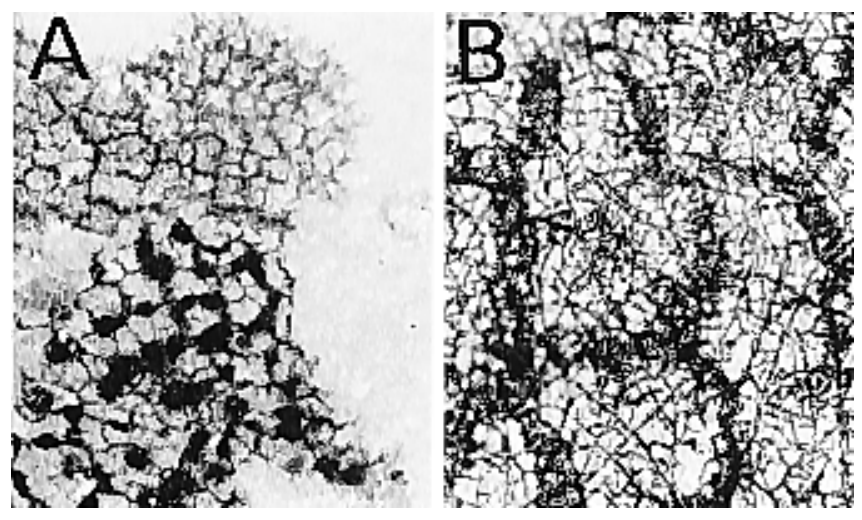

Fig. 4. Thallus morphology of rimate-like colonies. A, Honeycombed mycelia with a less dense reticulate network between ridges of a rimate-like colony that superficially appears to disrupt the cuticle on the fruit surface. Colonies can be with (upper) or without (lower) pycnothyria-like structures $(\times 18)$. $\mathbf{B}$, Ridges are areas of dense hyphal buildup without any association with cuticle disruption $(\times 150)$.
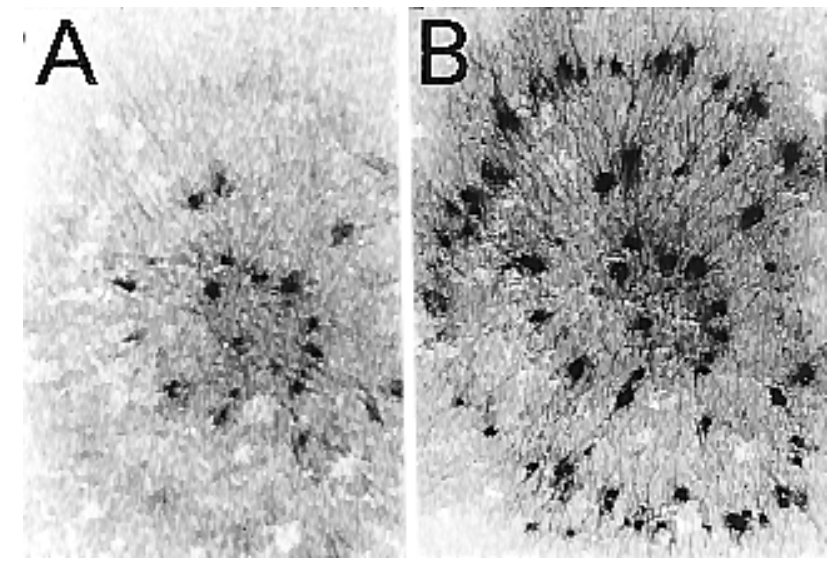

Fig. 5. Temporal development of sooty blotch symptoms. A, Immature ramose colony ( $\times 28)$; and $\mathbf{B}$, development of pycnothyria and mycelia in the colony after 14 days of incubation in a dew chamber $(\times 23)$.
Pycnothyria were never observed in fuliginous colonies (Fig. 3A). The thalli ranged from diffuse colonies that covered up to $30 \%$ of the fruit surface area to small, dark colonies up to $2 \mathrm{~cm}$ in diameter. The thallus always consisted of a reticulate network of mycelia (Fig. 3B). If interstitial areas of the reticulate network were filled with interlocking irregular cells, the colony appeared darker when viewed without magnification. Fuliginous colonies were irregular in shape with diffuse margins. After an extended period of high free moisture in 1992, conidiophores bearing conidia were observed projecting upward from the reticulate network on several fuliginous colonies on apple fruit (Fig. 3C). Conidiophores were 2 to 3 cells long and unbranched. Three to five conidia were arranged sympodially on the terminus of the conidiophore. Broken conidiophores without conidia were observed at other times and locations.

No true rimate colonies were observed on fruit from any of the locations. Colonies that formed honeycombed ridges amid a reticulate thallus were observed and appeared to fit this class (Fig. 4A). Closer evaluation showed that these honeycombed areas were not the result of mycelial growth within disrupted areas of the cuticle but were superficial ridges of dense mycelial growth on the surface of the fruit (Fig. 4B). Pycnothyria, observed infrequently on such colonies, were unlike those of ramose and punctate colonies. The surface was irregular and appeared to result from a buildup of sterile mycelial cells similar to the ridges. No spores were seen in these structures.

Symptom development. The thalli and immature pycnothyria of ramose and punctate sooty blotch colonies continued to develop when detached fruit were placed in a dew chamber (Fig. 5). Immature colonies that increased in mycelial density and produced new pycnothyria could be recognized easily as sooty blotch after incubation (Table 1). Colony diameter increased an average of 0.5 $\mathrm{mm} /$ week. Not all immature colonies produced new pycnothyria. Mature colonies increased in radial diameter $0.25 \mathrm{~mm} / \mathrm{week}$. Thallus density in these colonies increased more than those of immature colonies. New pycnothyria continued to be produced, and those

TABLE 1. Development of colonies of Peltaster fructicola on surface of apple fruit after 14 days of incubation in a dew chamber $18 \mathrm{~h}$ wet at $23^{\circ} \mathrm{C}$ and $6 \mathrm{~h}$ dry at $28^{\circ} \mathrm{C}$

\begin{tabular}{|c|c|c|c|c|}
\hline $\begin{array}{l}\text { Isolate } \\
\text { number }\end{array}$ & 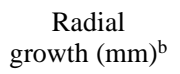 & $\begin{array}{c}\text { Maturing } \\
\text { pycnothyria }^{\mathrm{c}}\end{array}$ & $\begin{array}{c}\text { New } \\
\text { pycnothyria }^{d}\end{array}$ & Severity \\
\hline 1I & 2.3 & 2 & 1 & 3 \\
\hline $2 \mathrm{I}$ & 1.4 & 0 & 28 & 7 \\
\hline $3 \mathrm{I}$ & 0.3 & 6 & 0 & 7 \\
\hline $6 \mathrm{I}$ & 1.1 & 58 & 42 & 20 \\
\hline 7I & 0.2 & 0 & 0 & 20 \\
\hline $8 \mathrm{I}$ & 0.2 & 0 & 0 & 5 \\
\hline 9I & 0.4 & 0 & 0 & 4 \\
\hline $10 \mathrm{I}$ & 1.2 & 0 & 0 & 17 \\
\hline $11 \mathrm{I}$ & 2.5 & 13 & 0 & 15 \\
\hline $2 \mathrm{M}$ & 1.7 & 18 & 0 & 45 \\
\hline $3 \mathrm{M}$ & 0.0 & 0 & 0 & 20 \\
\hline $5 \mathrm{M}$ & 0.2 & 17 & 0 & 28 \\
\hline $7 \mathrm{M}$ & 0.0 & 0 & 0 & 5 \\
\hline $8 \mathrm{M}$ & 0.9 & 18 & 3 & 45 \\
\hline $13 \mathrm{M}$ & 0.7 & 24 & 0 & 15 \\
\hline $14 \mathrm{M}$ & 0.9 & 46 & 0 & 20 \\
\hline $15 \mathrm{M}$ & 0.0 & 59 & 24 & 25 \\
\hline $18 \mathrm{M}$ & 0.7 & 41 & 19 & 40 \\
\hline $20 \mathrm{M}$ & 0.0 & 0 & 39 & 20 \\
\hline
\end{tabular}

${ }^{a}$ Isolate colony number and maturity prior to incubation (I $=$ relatively immature; $\mathrm{M}=$ relatively mature). Colony was considered mature when readily visible without magnification. Immature colonies were not visible without a $\times 10$ lens.

${ }^{b}$ Increase in radial diameter of colony at widest point after incubation for 2 weeks.

${ }^{\mathrm{c}}$ Number of pycnothyria maturing during incubation period. A pycnothyrium was considered mature if a complete shield was formed.

${ }^{\mathrm{d}}$ Number of new pycnothyria formed during incubation period.

e Change in percentage of apple surface covered with subiculum after incubation period. 
that were immature prior to incubation completed development. The mycelial thallus and pycnothyria developed simultaneously as colony development expanded from its infection focus.

Fungal species determination. Three genera of fungi were associated with the various types of sooty blotch symptoms. On most of the ramose colonies examined, pycnothyria developed from a shield-shaped, cellular plate composed of irregularly shaped isodiametrical cells. Cell arrangement in the shield-shaped plate was irregular and nonradiate (Fig. 6B). As the pycnothyrium developed, a locule formed as the plate rose above the surface of the cuticle to form a convex shield (Fig. 6C). Several dark cell layers formed a dimitiate outer surface of the shield, and a hyaline cell layer lined the inner surface. Conidia were borne from this interior layer and were obovate, one-celled, hyaline, and measured 3.6 to $7.2 \mu \mathrm{m} \times 0.7$ to $1.1 \mu \mathrm{m}(6.4 \pm 2.6 \mu \mathrm{m} \times 0.8 \pm 0.1 \mu \mathrm{m})$. Conidia were contained in a gelatinous matrix, making them difficult to separate (Fig. 6B). Spore release occurred through fissures that formed along the surface of the shield of the pycnothyria (Fig. 6A). Mature pycnothyria were circular, were 81 to $113 \mu \mathrm{m}$ in diameter and 22 to $41 \mu \mathrm{m}$ in height $(97.3 \pm 11.3 \mu \mathrm{m} \times 26.3 \pm 6.3 \mu \mathrm{m})$, and were found throughout the growing season on both apple fruit and blackberry stems as well as in overwintered colonies. The combination of a dimitiate pycnothyrium without a well-defined ostiole, inverted hymenium, hyaline, single-celled conidia places this fungus in the genus Peltaster, which has been described as a new species, P. fructicola Johnson (12). Specimens (IMI 358519 and 358521) have been deposited at IMI.

Pycnothyria associated with punctate colonies developed in much the same manner as $P$. fructicola but were smaller ( 57 to $94 \mu \mathrm{m})$ in diameter $(73.6 \pm 7.1 \mu \mathrm{m})$. Conidia were hyaline, one-celled, cylindrical, and measured 3.1 to $4.2 \mu \mathrm{m} \times 0.5$ to $0.7 \mu \mathrm{m}(3.5 \pm 0.3 \mu \mathrm{m} \times$ $0.6 \pm 0.1 \mu \mathrm{m})$. This fungus may represent another new species of Peltaster.

Another pycnothyrial fungus was sometimes associated with a ramose colony type. These pycnothyria were superficially similar to Peltaster but contained distinctive conidia composed of 6 to 14 fusiform arms, 5 to 7 septate, and $\sim 50 \times 35 \mu \mathrm{m}$. This fungus was identified by B. C. Sutton as Geastrumia polystigmatis Batista \& M. L. Farr $(11,13)$. Upon initial colonization of the fruit, the subiculum was significantly more diffuse than that observed in ramose colonies associated with $P$. fructicola, but as the colony developed, it became darker and more dense. Geastrumia polystigmatis was observed less frequently than the other fungi associated with sooty blotch symptoms. A specimen has been deposited in IMI as IMI 358518.

The hyphomycete associated with the fuliginous colonies was identified by B. C. Sutton as Leptodontium elatius (G. Mangenot) De Hoog (4). Conidia of L. elatius were hyaline, smooth, thinwalled, cylindrical, often curved with inconspicuous basal scars, and measured 3.8 to $4.8 \times 1.6 \mu \mathrm{m}$. A culture was deposited in IMI as IMI 358514.

None of the fungi we observed associated with sooty blotch symptoms during this study matched Colby's description of $G$. pomigena nor did any herbarium specimens we examined that were labeled as $G$. pomigena.

Overwintering on apple fruit and blackberry stems. Typical mature pycnothyria were recovered from both ramose and punctate colonies on apples from both locations from late March through
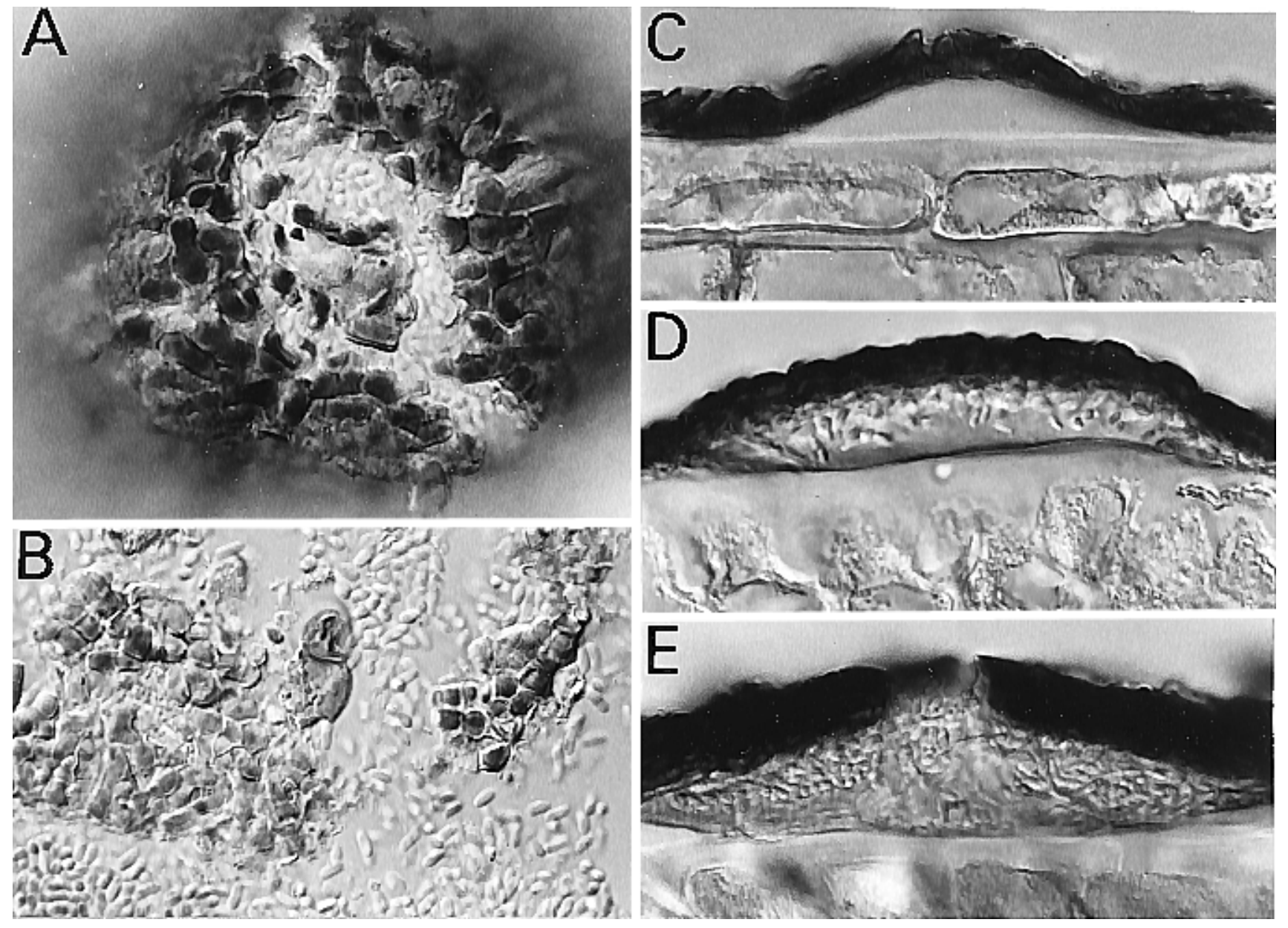

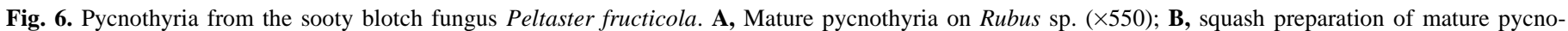

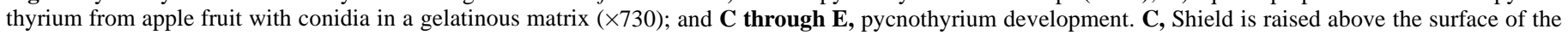

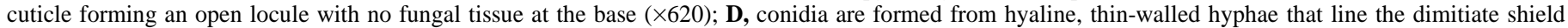
( $\times 510)$; and $\mathbf{E}$, when mature, the pycnothyrium is filled with hyaline conidia. There is a crack in the center of the shield ( $\times 570)$. 
May of 1992 and 1993. Fruiting bodies of sooty blotch fungi were observed more clearly on blackberry because there was less colonization by secondary fungi. Mature pycnothyria of $P$. fructicola were observed first on 23 March 1992 and 5 March 1993. Placement of a drop of water over the colony caused mature pycnothyria to swell, open, and release conidia. In histological cross-sections, conidia were observed forming within the locule of pycnothyria as early as February. Reproductive structures of L. elatius were observed on fuliginous colonies on blackberry on 4 November 1992. Conidiophores and conidia were similar to those described for fuliginous colonies on apple fruit. Remnants of conidiophores were observed on later dates throughout the winter, but they were always detached near the subiculum, and details of conidia or conidial scars could not be discerned. These structures were always associated with the reticulate mycelium of these colonies. Colonies did not develop further after placement in a mist bed or incubation chamber.

Pathogenicity of isolates on apple fruit. Of 18 isolates of $P$. fructicola, 8 produced sooty blotch symptoms when inoculated on detached fruit. Colonies originating from several isolates produced distinctive pycnothyria on the surface of the fruit. The subiculum of these colonies was not dense and radiated from a single focus, which is typical of ramose colony development. Of the 24 isolates of L. elatius used to inoculate detached fruit, $91 \%$ produced sooty blotch symptoms. These isolates formed a very light reticulate network of hyphae within the inoculation zone, which is characteristic of the fuliginous colony type; the 8 isolates that did not sporulate did not produce sooty blotch symptoms on detached fruit. Water-treated controls with $0.5 \%$ apple juice did not develop sooty blotch symptoms within the inoculation zone. Rapid deterioration of fruit after 14 days of incubation prevented long-term observation of colony development. L. elatius and $P$. fructicola were reisolated successfully from 27 and $81 \%$ of the fruit that developed symptoms, respectively. Isolates of $P$. fructicola were not recovered from inoculations made with $L$. elatius nor was the reverse observed.

Field inoculations were complicated by the high natural incidence and severity of sooty blotch at both locations. Incidence and severity measurements were used to establish correlations between the species of fungi used in the inoculation and the types of colonies observed on the fruit (Table 2). Sooty blotch severity was high at both the Central Crops and Mountain Horticultural Crops Research Station locations. Noninoculated fruit had 24 and $69 \%$ of their surface areas covered with sooty blotch at the end of the season at the Central Crops and Mountain Horticultural Crops Research stations, respectively. At the Central Crops Research Station, the proportion of total sooty blotch symptoms attributed to punctate, ramose, or fuliginous colonies was not different for the inoculated fruit compared to the control fruit. The proportion of sooty blotch attributed to punctate colonies was significantly greater than the noninoculated control for two of the three isolates of $P$. fructicola at the Mountain Horticultural Crops Research Station. Fruit inoculated with isolates of L. elatius had a higher numerical proportion of fuliginous colonies at both locations. Fruit inoculated with isolates that did not sporulate in culture had proportions of each colony type similar to the noninoculated control.

Characterization of sooty blotch on fruit from areas outside North Carolina. P. fructicola was identified on fruit collected from New York, Michigan, Virginia, West Virginia, Ohio, Kentucky, Illinois, Indiana, Alabama, and Massachusetts. Cultures from the ramose colonies formed conidia similar to those of $P$. fructicola characterized from North Carolina. Geastrumia polystigmatis was observed in collections from Michigan and Virginia, and punctate colonies with smaller pycnidia were observed on fruit from Michigan. Colonies resembling Geastrumia polystigmatis, but without mature conidia, were observed on fruit from Kentucky, Massachusetts, Alabama, Ohio, and New York.

Fuliginous colonies were present on fruit collected from New York and Illinois. Isolation from these colonies yielded cultures of L. elatius identical to those from cultures isolated from fruit in North Carolina. Rimate-like colonies were observed from isolations from New York, Illinois, Ohio, West Virginia, Kentucky, and Indiana. Isolations from these colonies produced fungi that did not sporulate in culture. Colonies with pycnothyria and conidia that matched Colby's description for G. pomigena were not observed on fruit from any state.

\section{DISCUSSION}

G. pomigena is accepted currently as the correct (and only) cause of sooty blotch of apple (18). Based on our results, we propose that sooty blotch of apples is caused by a complex of fungi, including L. elatius, P. fructicola, Geastrumia polystigmatis, and perhaps other as yet unidentified species of Peltaster and other fungal genera. Collections from other states indicate that these fungi are components of the apple sooty blotch complex in the eastern United States. We were unable to find G. pomigena in any of the collections.

When Colby (3) separated the pathogen causing sooty blotch from the pathogen causing flyspeck, he based his new genus, Gloeodes, on a fungus first described by Schweinitz (15) in 1834 as $D$. pomigena. This fungus was collected on mature cv. Newtown Pippin apples in Pennsylvania, and Schweinitz described it as "Spots orbicular, loose, [composed of] a radiating network of

TABLE 2. Sooty blotch colony types obtained after inoculation of apple with isolates of fungi associated with sooty blotch at two field locations in North Carolina

\begin{tabular}{|c|c|c|c|c|c|c|c|c|c|}
\hline \multirow[b]{2}{*}{ Isolate } & \multirow[b]{2}{*}{ Fungal species } & \multicolumn{4}{|c|}{ MHCRS $^{\mathrm{a}}$} & \multicolumn{4}{|c|}{$\mathrm{CCRS}^{\mathrm{a}}$} \\
\hline & & $\mathrm{SB}^{\mathrm{b}}$ & $\mathrm{P}^{\mathrm{c}}$ & $\mathrm{Ra}^{\mathrm{c}}$ & $\mathrm{F}^{\mathrm{c}}$ & SB & $\mathrm{P}$ & $\mathrm{Ra}$ & $\mathrm{F}$ \\
\hline C4P8 & Peltaster fructicola & 77 & 85 & 0 & 15 & 35 & 10 & 60 & 30 \\
\hline D3P5A & & 70 & 82 & 4 & 14 & 32 & 34 & 44 & 22 \\
\hline 2A3Ra1 & & 74 & 34 & 17 & 49 & 23 & 5 & 54 & 41 \\
\hline ES5P6 & Leptodontium elatius & 67 & 52 & 5 & 43 & 27 & 22 & 64 & 14 \\
\hline ES5F1 & & 57 & 28 & 11 & 61 & 30 & 16 & 44 & 40 \\
\hline ES5Ra2 & & 63 & 41 & 10 & 49 & 41 & 25 & 38 & 37 \\
\hline 2B4Ra5 & Unidentified & 61 & 32 & 20 & 48 & 29 & 5 & 72 & 23 \\
\hline 2BrRa4 & & 78 & 39 & 10 & 51 & 20 & 14 & 67 & 19 \\
\hline D3F1 & & 60 & 44 & 11 & 45 & 32 & 13 & 26 & 61 \\
\hline Control & & 69 & 53 & 10 & 37 & 24 & 15 & 58 & 27 \\
\hline LSD (0.05) & & NS & 30.6 & NS & NS & NS & NS & NS & NS \\
\hline
\end{tabular}

${ }^{a}$ MHCRS = Mountain Horticultural Crops Research Station, Henderson County, NC; CCRS = Central Crops Research Station, Johnston County, NC.

b $\mathrm{SB}=$ percentage of fruit surface area covered with sooty blotch.

${ }^{c}$ Proportion of area colonized with sooty blotch colony types punctate (P), ramose (Ra), or fuliginous (F) (sensu Groves [7]). 
very delicate black fibrils, for the most part sterile. Cells in the center aggregated, expanded, comparatively large. Spots hardly over $1 / 4$ inch [in diameter]." No mention was made of the presence of spores. Dothidea is an ascomycetous genus, and Saccardo (14) later transferred the fungus to Phyllachora, another ascomycetous genus, as Phyllachora pomigena. Saccardo (14) merely restated the original description of Schweinitz and again made no mention of spores. Colby (3) described Gloeodes as "Mycelium strictly superficial, dark colored, septate, profusely branched, often anastomosing, constituting a thallus, often fern-like in appearance but occasionally of other types; pycnidia dimitiate, membrano-carbonous, interior gelatinous; paraphyses present; conidia oblong, onecelled, hyaline." G. pomigena is further described as "Pycnidia dark brown, dimitiate, scattered or aggregated, rupturing irregularly; conidia oblong, sometimes slightly curved, one-celled, hyaline, 10-20 × 4-7 $\mu \mathrm{m}$; conidiophores short or lacking; paraphyses septate, gelatinous, slender, blunt, longer than the conidia." The type of the genus is based on D. pomigena. Colby published photographs (taken by J. W. Harshberger) of the exterior and interior of the packet containing the type of $D$. pomigena, deposited in the Herbarium of the Academy of Natural Sciences in Philadelphia, but gave no indication that he actually examined the original specimen. Our examination of the type specimen of $D$. pomigena revealed the presence of well-developed pycnothyrial-like bodies that, unfortunately, contained no spores. We were unable to locate any herbarium specimens deposited by Colby. Thus, only the written descriptions of Gloeodes and G. pomigena were available for study. Based on these descriptions and illustrations, the significantly larger spores of $G$. pomigena and an hymenium that completely surrounds the pycnidial cavity clearly indicate G. pomigena and P. fructicola are not conspecific.

Subsequent studies of sooty blotch generally added to the current confusion concerning the morphology and taxonomy of the pathogen. Baines and Gardner (2) isolated, either from spores or tissue, the "sooty blotch fungus" from fruits of apple and crabapple and from young twigs of 23 other hosts. Pycnothyria with mature spores were not found on apple or crabapple but were present on 12 of 23 other hosts. Conidia from these collections were mostly bicellular, with a few tricellular conidia, and measured 10 to $12 \times 2 \mu \mathrm{m}$. Cultural characteristics of the isolates from the different hosts varied, but most produced two-celled conidia that sometimes became multicellular after germination. Conidia formed in culture were slightly larger than those formed on the hosts. Symptoms typical of sooty blotch were produced on apples after inoculation with cultures from apple and nine other hosts.

Subsequent to Colby, Groves (7) examined numerous sooty blotch thalli on apple fruit and found marked differences among many of them. On the basis of general morphology of the thalli, he divided them into four general types. Isolates from these types varied significantly in their cultural characteristics, but Groves was unable to demonstrate any relationship between colony types in culture and thallus types on apples. Spores, produced on most isolates at $20^{\circ} \mathrm{C}$, were generally cigar-shaped, and the number of septa varied from 0 to 5 , mostly from 1 to 3 . Size varied from $3.08 \times 13.8 \mu \mathrm{m}$ for one-celled spores to $3.14 \times 31.4 \mu \mathrm{m}$ for five-celled spores. Hickey (9) made more than 1,000 isolations from apple and crabapple fruit and from twigs and stems of eight other plant species. Like Groves (7), Hickey (9) observed the variability of the sooty blotch thalli on apple and segregated them into the four types recognized by Groves. He was able to reproduce the different types by inoculation on apple fruit with spores from cultures made from the respective types from apple fruit. Hickey (9) also found considerable variation in cultural characteristics among his isolates, which generally produced spores with the same general size, shape, and septation reported by Groves (7).

Even with the significant variation in the thalli on apple fruit and in cultural characteristics of isolates made from these thalli and with spores that differed in size and number of septa from the original description of $G$. pomigena, Baines and Gardner (2), Groves (7), and Hickey (9) all accepted the name G. pomigena as the correct name for the causal agent of sooty blotch. Hickey (9) did, however, consider giving different subspecific names to the different types of thalli but could not decide on what subspecific designations to use. Apparently, most of the collections from apple made by these authors did not contain spores, and none of them reported details of pycnothyrial morphology of the fungus or fungi with which they were working.

Based on our studies, the role of $G$. pomigena in the sooty blotch complex is unclear. None of the herbarium specimens labeled as $G$. pomigena that we examined during the course of this study matched Colby's (3) description of that fungus. Some specimens so labeled contained a fungus identical to $P$. fructicola (US 0391379 and US 0391383), and others (US 0931382, US 0391381, and US 0391377) were sterile. The morphology of the colonies of these latter specimens was similar to that of colonies associated with L. elatius.

In addition, we examined a large number of fruit from North Carolina, as well as fruit from other states, but were unable to find a fungus that matched Colby's (3) description of G. pomigena. It is possible that our sample size, especially from other states, was too small to detect $G$. pomigena. Similarly, we were unable to find the two- to five-celled spores reported by Baines and Gardner (2), Groves (7), and Hickey (9). These researchers may have observed germinated conidia of $P$. fructicola that give the appearance of multicelled conidia.

$P$. fructicola was the most common fungus associated with sooty blotch on apples from North Carolina as well as on samples of fruit from other states (data not presented). In contrast, Sutton and Sutton (17) reported that the punctate mycelial type, which is associated with a fungus similar to $P$. fructicola but with smaller pycnothyria and conidia, was the most abundant mycelial type observed in most orchards in North Carolina. Our pathogenicity studies and reisolations provided evidence that $P$. fructicola and $L$. elatius are able to cause sooty blotch symptoms. Sooty blotch fungi are difficult to isolate due to many contaminating microorganisms on the surface of plant parts. All researchers who have worked with sooty blotch have expressed difficulty in isolating the causal agent due to contamination by other microorganisms. Our method of teasing a large number of conidia from mature pycnothyria of Peltaster into a drop of water was a very effective means of isolation.

We did not find reproductive structures associated with rimatetype colonies on fruit nor in cultures from isolations. The identity of the fungus or fungi causing these sooty blotch symptoms remains uncertain. Comparisons in culture were useful for studying the occurrence of L. elatius and P. fructicola on apples collected from locations other than North Carolina. Reproductive characters for isolates of Peltaster from ramose and punctate colonies in other geographic areas matched those of the collections from North Carolina on apple fruit and cultures. Fuliginous colonies were observed less frequently on fruit outside North Carolina, which may account for our inability to collect isolates of L. elatius from a broad geography.

The identification of Geastrumia polystigmatis from ramose colonies provides additional evidence that both apple fruit and blackberries are hosts to many fungi that have an epiphytic relationship with the host. Geastrumia polystigmatis was previously reported only on Andira jamaicensis in the Dominican Republic and on Hymenocardia acida and Costus afera in Tanzania (13). This fungus is thought to be widely distributed, even though it rarely has been reported. Similarly, L. elatius has been reported in Nigeria, Great Britain, Canada, the United States, France, and Germany on diverse species, including Populus, Abies, Betula, Prunus, and Pseudotsuga (4). It is well documented $(5,6,8,10)$ that many different fungi occupy the same ecological niche on the surface of plants. We feel it is likely that additional apple sooty blotch fungi will be identified. 


\section{ACKNOWLEDGMENTS}

The use of trade names in this publication does not imply endorsement by the North Carolina Agricultural Research Service nor criticism of similar ones not mentioned. We thank B. C. Sutton and A. Sivanesan of the International Mycological Institute, and C. Hodges of North Carolina State University for assistance in fungal determinations. We also thank J. McVay, K. Yoder, A. Biggs, A. Jones, D. Rosenberger, D. Cooley, H. Shafer, M. Ellis, and S. Ries for supplying disease specimens for our studies.

\section{LITERATURE CITED}

1. Baines, R. C. 1932. Hosts and cultural characteristics of the apple sooty blotch fungus. M.S. thesis. Purdue University, West Lafayette, IN

2. Baines, R. C., and Gardner, M. W. 1932. Pathogenicity and cultural characters of the apple sooty-blotch fungus. Phytopathology 22:937-952.

3. Colby, A. S. 1920. Sooty blotch of pomaceous fruits. Trans. Ill. Acad. Sci. 13:139-179.

4. De Hoog, G. S. 1977. Rhinocladiella and allied genera. Pages 1-140 in: Studies in Mycology. No. 15. Centraalbureau voor Schimmelcultures, Baarn, the Netherlands.

5. Farr, M. L. 1985. Amazonian foliicolous fungi. II. Deuteromycotina Mycologia 78:269-286.

6. Farr, M. L. 1987. Amazonian foliicolous fungi. IV. Some new and critical taxa in Ascomycotina and associated anamorphs. Mycologia 79:97116.

7. Groves, A. B. 1933. A study of the sooty blotch disease of apples and causal fungus Gloeodes pomigena. Va. Agric. Exp. Stn. Bull. 50:1-43.

8. Hansford, C. G. 1946. The foliicolous ascomycetes, their parasites and associated fungi. Mycol. Pap. 15:1-240.

9. Hickey, K. D. 1960. The sooty blotch and flyspeck disease of apple with emphasis on variation within Gloeodes pomigena (Schw.) Colby. Ph.D. dissertation. The Pennsylvania State University, University Park.

10. Hohnel, F. v. 1910. Fragmente zur Mykologie. Math.-Naturwiss. Klasse Abtielung I 119:451.

11. Johnson, E. M., and Sutton, T. B. 1994. First report of Geastrumia polystigmatis on apple and common blackberry in North America. Plant Dis. 78:1219.

12. Johnson, E. M., and Sutton, T. B. 1996. Peltaster fructicola: A new species in the complex of fungi causing apple sooty blotch. Mycologia 88: 114-120.

13. Pirozynski, K. A. 1971. Note on Geastrumia polystigmatis. Mycologia 63:887-901.

14. Saccardo, P. A. 1883. Phyllachora pomigena (Schw.) Sacc. Syll. Fung. 2:622.

15. Schweinitz, L. D. 1832. Dothidea pomigena. Transactions of the American Philosophical Society, New Series, Philadelphia. Page 232.

16. Sutton, A. L. 1993. Distribution of mycelial types of Gloeodes pomigena on apples in North Carolina and the effect of captan on their incidence, severity, and distribution. M.S. thesis. North Carolina State University, Raleigh.

17. Sutton, A. L., and Sutton, T. B. 1994. The distribution of the mycelial types of Gloeodes pomigena on apples in North Carolina and their relationship to environmental conditions. Plant Dis. 78:668-673.

18. Sutton, T. B. 1990. Sooty blotch and flyspeck. Pages 20-22 in: Compendium of Apple and Pear Diseases. A. L. Jones and H. S. Aldwinkle, eds. The American Phytopathological Society, St. Paul, MN.

19. Zaring, D. 1929. Studies on sooty blotch of apples. M.S. thesis. Purdue University, West Lafayette, IN. 